\title{
An Intelligent Approach Based on Embedded System Design for Telemedicine Application
}

\author{
Aproximación inteligente basada en el diseño de sistemas \\ integrados para la aplicación de la telemedicina
}

Mihir Narayan Mohanty ${ }^{1} \bowtie$

${ }^{1}$ ITER, Siksha 'O' Anusandhan, Bhubaneswar, Odisha, India

Department of Electronics and Communication Engineering, ITER, Siksha 'O' Anusandhan, (Deemed to be University), Bhubaneswar, Odisha, India, Pin-751030. Email:mihirmohanty@soa.ac.in

Received on: October $5^{\text {th }}, 2017 \quad$ Accepted on: January $20^{\text {th }}, 2018 \quad$ Available online: May $1^{\text {st }}, 2018$

How to cite this article: M. N. Mohanty, "An Intelligent Approach Based on Embedded System Design for Telemedicine Application", Ing. Sol., vol. 14, no. 25 (Special issue), pp. 12, May 2018. doi: https://doi.org/10.16925/.v14i0.2227

\section{Abstract}

Introduction: The present research was conducted at Sikha 'O' Anusandan (deemed to be University) in 2017. Telemedicine application in the field of medicine creates a new age. Accordingly, it requires technology to be compatible. Easy access and fast processing are the major focuses in different applications. In this paper, an approach has been considered to diagnose heart diseases.

Methods: The model is designed using fuzzy logic in which the rule-based principle is applied to satisfy the objective. The model is developed keeping a view over the multi-agent system. The diagnosis of the patient is performed using Fuzzy Inference System (FIS).

Results: The pathological test results will help to form the rules of the model and can work for the diagnosis in a convenient way. Furthermore, the results of detection are communicated through Internet and sms for monitoring and post care purpose of supporting loT application.

Conclusion: The simulated result shows its performance can be helpful to physicians as well as patients from remote places.

Originality: The model is proposed for disease detection and monitoring patients on remote locations. Also, distributed agents are proposed to act on a common platform using Internet for the benefit of society. This will save time for physicians and travelling costs for the patient.

Limitations: The research results can be practically implemented in new medical equipment for hospitals with earlier equipment.

Keywords: diagnosis, fuzzy inference system, fuzzy rule base, multi-agent system. 


\title{
Aproximación inteligente basada en el diseño de sistemas integrados para la aplicación de la telemedicina
}

\author{
Resumen \\ Introducción: la presente investigación se realizó en Sikha 'O' Anusandan (la cual se considera una universidad) \\ en 2017. La aplicación de la telemedicina en el campo de la medicina genera una nueva era. En consecuencia, \\ requiere que la tecnología sea compatible. Las características principales que se demandan de dichas aplicaciones \\ son el fácil acceso y el procesamiento rápido. Este estudio se aproxima a la telemedicina para el caso de diagnosis \\ de enfermedades cardíacas.
}

Métodos: el modelo se diseña mediante una lógica difusa en la que se aplica el principio basado en reglas para satisfacer el objetivo. El modelo se desarrolla teniendo en cuenta el sistema de agentes múltiples. El diagnóstico del paciente se realiza con el sistema de inferencia difusa (FIS).

Resultados: Ios resultados de la prueba patológica ayudarán a formar las reglas del modelo y pueden aportar para el diagnóstico de manera conveniente. Además, los resultados de la detección se comunican a través de Internet y sMs para fines de seguimiento y cuidado posterior de la aplicación loT.

Conclusión: el resultado simulado muestra que su desempeño puede ser útil tanto para médicos como para pacientes en lugares remotos.

Originalidad: se propone el modelo para detectar enfermedades y monitorear pacientes situados en locaciones remotas. Además, se propone que agentes distribuidos en una zona actúen sobre una plataforma común utilizando internet para el beneficio de la sociedad, esto ahorrará tiempo a los médicos y costos de traslado o transporte del paciente.

Limitaciones: los resultados de la investigación se pueden implementar de forma práctica en nuevos equipos médicos para hospitales con equipos ya existentes.

Palabras clave: diagnóstico, sistema de inferencia difusa, base de reglas difusas, sistema multiagente.

\section{Aproximação inteligente baseada no design de sistemas integrados para aplicativos de telemedicina}

\begin{abstract}
Resumo
Introdução: a presente pesquisa foi realizada na Universidade de Sikha '0' Anusandan, em 2017. 0 aplicativo de telemedicina no campo da medicina gera uma nova era. Em consequência, requer que a tecnologia seja compatível. 0 acesso fácil e o processamento rápido são as principais características esperadas dos diferentes aplicativos. Neste estudo foi considerada uma aproximação para diagnosticar as doenças cardíacas.

Métodos: 0 design do modelo é feito através de uma lógica difusa, na qual o princípio baseado em regras para satisfazer 0 objetivo é utilizado. 0 modelo é desenvolvido tendo em conta o sistema de agentes múltiplos. 0 diagnóstico do paciente é realizado utilizando o sistema de inferência difusa (FIS).

Resultados: os resultados do exame patológico ajudarão a formar as regras do modelo e podem contribuir para 0 diagnóstico de forma conveniente. Além disso, os resultados do exame são comunicados, por internet e sms, para fins de seguimento e cuidado posterior do aplicativo loT.

Conclusão: o resultado simulado mostra que seu desempenho pode ser útil tanto para médicos quanto para pacientes em lugares remotos.

Originalidade: é proposto o modelo para detectar doenças e monitorar pacientes situados em lugares remotos. Além disso, é proposto que agentes distribuídos em determinadas zonas utilizem uma plataforma comum, fazendo uso da internet para beneficiar a sociedade, o que economizará tempo para os médicos e custos de traslado e/ou transporte do paciente.

Limitações: os resultados da pesquisa podem ser inseridos de forma prática em novas equipes médicas para hospitais com equipes já existentes.
\end{abstract}

Palavras-chave: base de regras difusas, diagnóstico, sistema de inferência difusa, sistema multiagente. 


\section{Introduction}

Intelligent techniques are employed in many application areas to improve reliability and smart service. One of the most important applications is health care systems. Researchers are trying to improve these units to provide better service to patients. The outcomes can support physicians also in a better way in comparison to the previous methods. It tends towards a multi agent system concept and its research has spread over most of the areas such as Computer science, Engineering, Medicine, business organizations, etc. The system comprises a set of models based on the knowledge base of related field. These models may be developed and revised. Though the objective of multi agent system is for compression and co-ordination between agents, it requires refinement according to the desire of the client agents. The system has four types of features:

1. Communication among agents

2. Autonomy

3. Agent behavior

4. Heterogeneity

Each feature can be developed through software modules for particular environments. To form the system agents we have the software design paradigms based on the environment. In this work we attempt to develop the module of diagnosis and monitoring subsystems of an e-health care system.

Health consciousness has expanded the life span of the human being. To improve the quality of life in society, smart health service is indispensable. E-health is the substantial way to fast service. By this technology, we can address and collect a database of the most common chronic diseases and their complications, which could potentially help to elucidate the main reasons and reduce the risk of their occurrence. E-healthcare plays a vital role in this area. By virtue of this, quality health service can be provided in rural areas that are far from reach of medical facilities. Also the home monitoring of health care can save both time as well as patient's expenses [1]. E-health technologies have a significant future impact on patient's empowerment in health maintenance and decision-making supporting self-care.
The healthcare units consists of several factors and some of the agents, as healthcare communicate in smart ways and also provide support to different agents like patient, patho-care, physicians, hospitals, and also rural areas. It is termed as e-health. It is inter-changeable with health information; in most of the cases, these are useful to store the health records support for telemedicine and services to the consumers [2]. Due to the fact that population in rural areas is higher than in urban areas the e-health service can be useful for patients and practitioners. The system may take the help of wireless communication or Internet or a mobile based system. Therefore, another issue is that patients have multiple health records in different health care units based on their problems. It is necessary to access that information from different sources and to manage the flow for treatment. So for this issue the system may use the e-prescription and suggestions to the patient of different places also. This became a great challenge for researchers with insufficient infrastructure. Therefore, this system is helpful to the patients and can be allotted to the critical patients. To detect and monitor cardiac disease in intelligent ways is a great challenge in the present scenario. Co-ordination among health care units such as patient, physician, health records, diagnostic centers, etc., can serve effectively.

A complex system can be understood and managed in a better way by modeling and simulation. An agent is a single entity that has knowledge, objective and capability of carrying out certain tasks. An interoperable self-independent co-operative multiagent system can address the complex environment involved in healthcare [3], [4]. In the field of computational intelligence design, fuzzy logic has proved itself as a powerful tool for developing an intelligent knowledge base system in healthcare. Various biosensors fitted to the body of the patient provide physical parameters to the fuzzy logic controller. The fuzzification of these data is transformed into fuzzy variables. These fuzzy variables are easy to understand and their modeling helped to reduce the human error in prediction [5], [6]. Cardiac diseases and heart monitoring can be diagonized by using FPGA architecture. It can reduce the subfuctional units and is able to increase the efficiency of the system [7].

Communication is an inevitable tool in this system. Transfer of health record without loosing its originality is a great challenge. Researchers 
have tried to attain communication among all the agents using various techniques. Telemedicine is frequently used for patient monitoring and diagnosis of diseases [8]. An embedded system is used to provide a partial solution to the diagnosis of remote area patients. The research on this field encouraged us to implement fuzzy logic for cardiac disease detection and the information regarding communication is established with the help of a microcontroller-based module. Mainly the electronic healthcare systems are focused on monitoring a particular health problem or health state using Medical Sensor Networks. These systems help the patient monitoring and observing without hospitalizing [9], [10].

In this work we have considered one of the chronic diseases as the cardiac problem that may occur due to an aging effect. In section 2 , some of the related works have been cited and the proposed methodology is explained in section 3. The possible outcome is shown in section 4 and section 5 concludes this piece of work.

Though different approaches have been made since long ago, still there is an implementation and accuracy gap. Based on the literature, our proposed work is explained in the following section.

\section{Literature Review}

Research has been carried out for the development of e-health care system since long ago. Some of them focused on multi-agent system whereas most of them analyze the diagnostic center. Attention has been given to the field of signal and image processing along with telemedicine systems [11]. This section provides the related work in this field. Little amount of works have based themselves on this area. Some of those are cited in this section to review literature.

In [12], authors developed a processor for transmission of signals from a patient over a Bluetooth link to a mobile telephone. Various algorithms were introduced to reduce the number of rules and searches with high predictive accuracy for heart diseases. Models were proposed for feature selection of clinical data to detect patients with CHD. Imaging technique was used on coronary angiography for predicting the risk factors of CHD. Particle swarm optimization (PSO) was used for optimization to obtain a better accuracy of $99.73 \%$.
Adaptation and efficient use of suitable algorithm in the development of effective healthcare systems has been a major challenge as the information recovered from the wearable devices in e-health care systems is complex in nature. Using suitable algorithms can be represented to the physicians for decision-making and detection of diseases. Different authors [13] have investigated and obtained considerable inputs on the development of suitable healthcare systems including Electromechanical Wave Imaging (EWI) and Wearable Smartphone based platforms for detection and diagnosis of critical diseases. Detection and proper identification of diseases desires the selection of efficient classification methods. Among different classifiers, the Relative Associated Density (RAD) method, Artificial Neural Network (ANN) and Decision Tree Method; these have been quite effective in this direction. ANN is a type of classifier that resembles the biological neurons of human beings and can describe complex input and output relations efficiently. Few of the classifiers such as RAD, ANN, k-NN (k nearest neighbor) and decision tree have been applied to detect the cardiac diseases successfully; this has been the major influence in the field of health care [14]. Classifiers such as random forest classifier and support vector machine classifier (svM) have been used to recognize heart beat signals to explore for Hypertrophic Cardiomyopathy Identification [15]. Features representing these signals received from the testing machines have to be robust and reliable so as to describe the symptoms of these diseases. Different feature extraction techniques and algorithms have been experimented for monitoring complicated health related issues. Use of software tools and suitable feature extraction methods dealing with testing and measurement for abnormal heart sounds has been investigated in [16]. Prediction algorithm that can detect these diseases is one of the major tasks. Efficient prediction algorithm that can suitably describe the symptoms of the diseases from the signals received during testing of the patients has been explored in [17]. Raspberry Pi and Digi-Xbee series boards are used to implement the setup for hardware [18], [19]. The embedded web server using ARM processor has been designed and implemented [20]. In addition, ARM processor has been used in Linux operating system environments [21], [22]. 


\section{Methods}

The proposed system is shown in Fig. 1. It consists of intelligent agents that detect the disease. Once the abnormalities are detected, it communicates with the physician as well as with the patient. After that, the different agents that follow are defined by the intelligent detector using fuzzy logic.

Patient agent: Patient who is suffering will communicate to the hospital registration module with the help of a communicating device like a mobile phone or PC.

Hospital registration: The hospital registration will store the parameters in the server and forward the parameters to Doctor 1 agent for recommendation of pathological tests.

Doctor 1: Doctor 1 is an agent that acts like the OPD of the hospital. It uses the fuzzy logic for suggesting the pathological tests required for the patient.

Diagnostic Centre Agent: The patient's data that has been generated is sent to the diagnostic agent for analysis and disease prediction. The server sends as well as receives the data from this unit.

Doctor 2 or Specialist Agent: This communicates with the doctor. It will send email/sms to the doctor regarding the abnormality for getting the prescription. The prescription is generated and delivered to the patient. If the doctor requires investigating any medical history of the patient or timeto-time variation of the parameters of the patient, he can access the server for monitoring purposes.

Server Agent: Server delivers the information to all. It sends the data for diagnosis to the diagnostic center and receives the report. Similarly, the reports are sent to the physician. The decision of data flow and management of overall operations is done this way.

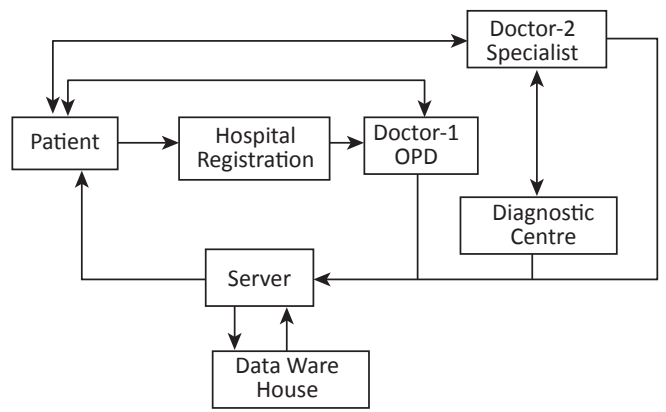

Fig . 1. Multi-agent Structure for Patient Consultancy using Fuzzy System

Reference: the authors
Fig 2 describes the data flow in a diagnostic agent. The patient is advised to send his symptoms to the diagnostic center. Based on those data the diagnostic center analyzes to specify the disease. In this work, we used fuzzy inference system for detecting heart related diseases.

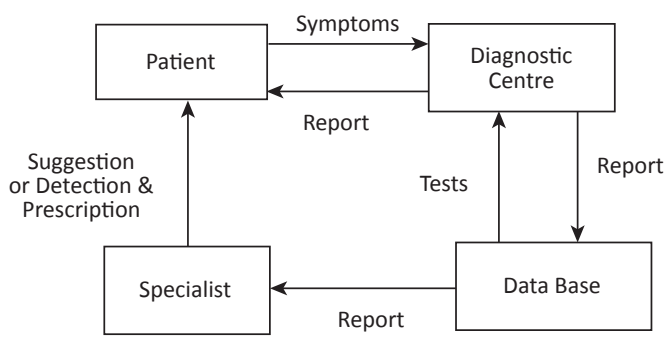

Fig . 2. Diagnostic Centre Structure Reference: [16]

Fig. 3 describes the agent-based consultancy of the patient. The patient uploads his symptoms as well as his parameters to the server through hospital registration. Uploaded data is forwarded by the server for testing at the diagnostic center. If the condition of the patient is normal then an email or sMs is sent to the patient along with remedial steps for him to take depending on his health condition.

If any abnormality is observed then the diagnostic center agent will inform the concerned specialist i.e. Doctor 2 for immediate action. Here the fuzzy IF THEN rule is implemented for providing information to the doctor. The doctor can check the reports of the patient by sending a request to the server.

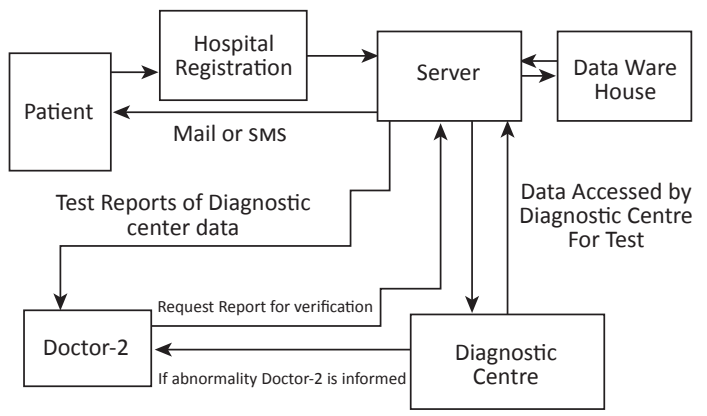

Fig. 3. Information Centre Reference: [16] 


\section{Heart disease diagnosis using fuzzy interference system}

Rule based fuzzy system acts as the diagnosis center. The tests and results are analyzed using if-then-else logic. The fuzzy set is defined as $A=\Sigma x i \in X \mu A(x i) /$ $x i$, if $X$ is a collection of discrete objects, and $A=\int X \mu A(x) / x$, if $X$ is a continuous space [36]. For the system's design, triangular membership function is used and explained as follows.

It is specified by three parameters that can be formulated for the specific problem.

The set of parameters is $\{a, b, c\}$

Triangle $(x ; a, b, c)=0$ if $x \leq a$

$=(x-a) /(b-a)$ if $a \leq x \leq b$;

$=(x-b) /(c-b)$ if $b \leq x \leq c$;

$=0$ if $c \leq x$

The rules can be implemented for the triangular membership function. IF-THEN rule has the form "If $\mathrm{x}$ is $\mathrm{A}$ then $\mathrm{y}$ is B" where A and B are linguistic values defined by fuzzy sets on universes of discourse $X$ and $Y$, respectively. " $x$ is $A$ " is called antecedent and " $y$ is $B$ " is called consequent.

The problem for the diagnostic agent is formulated as follows.

For the adaptive cardiac disease detection using the fuzzy inference system, the following parameters are taken:

- $\quad$ BP taken in the range 90 to 190 (in $\mathrm{mm} \mathrm{Hg}$ )

- Serum Cholesterol in the range 120-560 (Mg/dl)

- $\operatorname{FBs} 110(\mathrm{Mg} / \mathrm{dl})$

- ECGST-Twave abnormality

The above inputs are chosen for the following reason

- The heart function is normal if BP is normal. If $\mathrm{BP}$ rises abnormally then this indicates the patient may suffer from cardiac disease. So вP is concerned with heart disease detection.

- Deposition of TG narrows the blood circulation path. Excess of cholesterol in blood gradually narrows the circulatory path and cardiac disease may be detected in the patient.

- Sugar is the silent killer. If it is beyond the normal value then there are chances of heart disease.

- ECG signal is the best predictor of heart disease. If ST-T wave abnormality is observed even though all the above tests show normal values, the patient will still be diagnosed with a cardiac condition.

The fuzzy inference system uses the above-mentioned parameters, BP, FBS, cholesterol and ECGST-T abnormality, as its inputs, and detection as its output. The linguistic variables used with fuzzy sets with different data such as ECG, BP, FBS, etc., have been tabulated in Tables 2-4.

Table 1. Linguistic variables versus fuzzy set for вр and ғвs

\begin{tabular}{cc}
\hline Linguistic variable & Fuzzy set \\
\hline BP & Low, normal, high \\
FBS & Low, normal, high \\
Detection & No, yes \\
\hline
\end{tabular}

Reference: the authors

\begin{tabular}{|c|c|}
\hline $\begin{array}{l}\text { The membership functions input } \\
\text { for BP }\end{array}$ & Range \\
\hline Low & {$[40 / 90-70 / 100]$} \\
\hline Normal & [70/110-80/120] \\
\hline High & [90/130 and above] \\
\hline $\begin{array}{l}\text { The membership functions input } \\
\text { for FBS }\end{array}$ & $\underline{\text { Range }}$ \\
\hline Low & {$[60-70]$} \\
\hline Normal & [70-120] \\
\hline High & [120 and above] \\
\hline
\end{tabular}

Table 2. Linguistic variables versus fuzzy set for EGG

\begin{tabular}{cc}
\hline Linguistic variable & Fuzzy set \\
\hline ECG & Low, normal, high \\
Detection & No, yes \\
\hline
\end{tabular}

Reference: the authors

The membership functions input for ECG

Low

High
Range

[0]

[1] 
Table 3. Linguistic variables versus Fuzzy set for ECG, BP and FBS

\begin{tabular}{cc}
\hline Linguistic variable & Fuzzy set \\
\hline ECG & Normal, abnormal \\
BP & Low, normal, high \\
FBS & Low, normal, high \\
Detection & No, yes \\
\hline
\end{tabular}

Reference: the authors

\begin{tabular}{lll}
$\begin{array}{ll}\text { The membership functions input } \\
\text { for ECG }\end{array}$ & \multicolumn{2}{l}{ Range } \\
Low & 0.5 \\
Normal & 1 \\
Abnormal & \\
$\begin{array}{ll}\text { The membership functions input } \\
\text { for BP }\end{array}$ & {$[40 / 90-70 / 100]$} \\
Low & {$[70 / 110-80 / 120]$} \\
Normal & {$[90 / 130$ and Above $]$} \\
High & \multicolumn{1}{c}{ Range } \\
The membership functions input & \\
for FBS & {$[60-70]$} \\
Low & {$[70-120]$} \\
Normal & {$[120$ and above $]$} \\
High &
\end{tabular}

The membership function of different data inputs such as BP, FBS, cholesterol and ECG are considered with triangular membership function and are shown in Fig. 4. The membership function of input ECG is shown in Fig. 5.

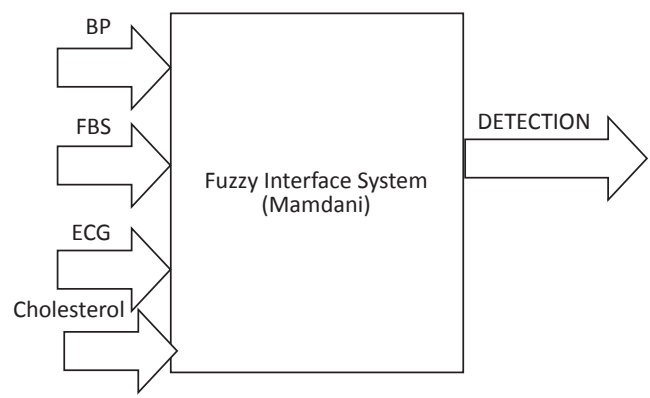

Fig. 4. Four inputs for fuzzy inference system Reference: the authors
Table 4. Linguistic variables used with fuzzy set for ECG, BP and FBS

\begin{tabular}{cc}
\hline Linguistic variable & Fuzzy set \\
\hline ECG & Low, normal, high \\
BP & Low, normal, high \\
FBS & Low, normal, high \\
Cholesterol & Low, normal, high \\
Detection & No, yes \\
\hline
\end{tabular}

Reference: the authors

The membership functions input

$\underline{\text { Range }}$ for ECG

Low 0

Normal

Abnormal

1

The membership functions input for BP

Low

Range

Normal

[40/90 -70/100]

High

[70/110-80/120]

[90/130 and above]

The membership functions input $\underline{\text { for FBS }}$

Low

$\underline{\text { Range }}$

Normal

[60-70]

[70-120]

High

[120 and above]

The membership functions input for cholesterol

Low

Range

Normal

[130-230]

High

[230 and above]

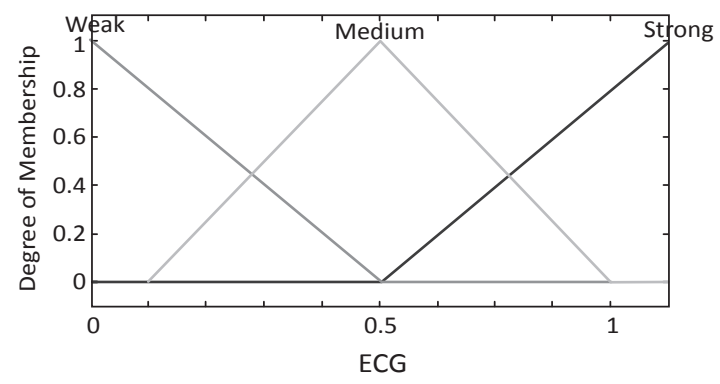

Fig. 5. Membership Function of input ECG Reference: the authors 


\section{Results}

Once the detection is performed, it has to be communicated to different agents. The communication module may consist of either Internet technology or the mobile network, or both through smart devices. The digital mobile communication system is widely used due to its high reliability, sms (Short Message Service) also since it is accessible for everyone that has a mobile phone. It is also possible to have Internet in smart mobile systems, as well as the computer terminal. In case of using a computer terminal, a modem is required as an additional device. In this case, it has been verified for both and the result is shown in the results section.

The FIs editor window for two inputs and outputs is shown in Fig. 6. The fuzzy rule viewer for BP and ECG for detection of cardio-vascular disease is shown in Fig. 7.

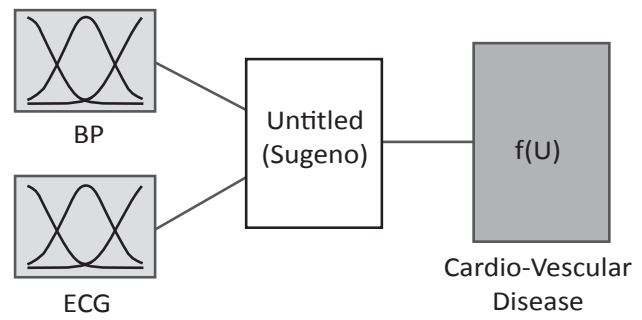

Fig. 6. FIs editor window showing the inputs and outputs Reference: the authors
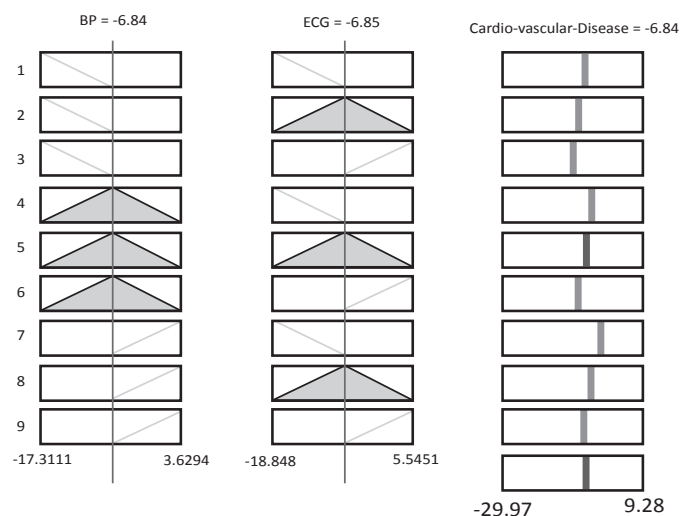

Fig. 7. Fuzzy rule viewer for BP and ECG for detection of cardio-vascular disease Reference: the authors
The FIS rule formation for BP and ECG for detection of cardio-vascular disease is as follows:

1. If вP is low and ECG is poor then cardio-vascular disease is detected

2. If $\mathrm{BP}$ is low and ECG is moderate then cardio-vascular disease is detected

3. If вP is low and ECG is good then cardio-vascular disease is undetermined

4. If $\mathrm{BP}$ is medium and ECG is poor then cardio-vascular disease is undetermined

5. If вP is medium and ECG is moderate then cardio-vascular disease is not-detected

6. If BPis medium and ECG is good then cardio-vascular disease is not detected

7. If $\mathrm{BP}$ is high and ECG is poor then cardio-vascular disease is detected

8. If $\mathrm{BP}$ is high and ECG is moderate then cardio-vascular disease is detected

9. If вP is high and ECG is good then cardio-vascular disease is detected

The accessed data is presented in Table 5 and the pop-up menu at the time of sending and receiving mail/sms is shown in Fig. 8. With this report it is possible to diagnose, as the data shows, it appears to be that the patient is suffering from cardiac problems.

Table 5. Measuring values of different paramenters

\begin{tabular}{ccc}
\hline вР & Cholesterol & FBS \\
\hline $95 / 160$ & 400 & 250 \\
$90 / 140$ & 350 & 190 \\
\hline
\end{tabular}

Reference: the authors

Similarly the SMS service using GSM module is represented in Fig. 8. Depending upon the various parameters sent by the patient it is possible to detect that the patient is okay.

\subsection{Hardware module implementation using Raspberry Pi}

Raspberry Pi acts as an Internet Gateway Device and has the ability to route data coming from the wSN network to internet and send data coming from internet to wSN network. It hosts an Embedded Web Server (EWs) on it for implementation of TCP/ 
SMS/MMS

3:31 PM

PATIENT ID-375

BP-80/130 FBS-100,

Received

CHOLESTEROL-180,

ECG-NORMAL,

STATUS-OK

Fig. 8. Snapshot of sms received from the server

Reference: the authors

IP protocols [28]-[31]. By implementing TCP/IP stack on microcontroller we can control and monitor device status through the webpage. The embedded web server is used to serve web pages. Giving the IP address provided to EWs the web pages can be accessed.

Fig. 9 shows the architecture of the proposed system. The major components of door access control are: Wireless Control Unit (wCU) and Wireless Information Unit (WIU). The two units are linked to each other by radio transceivers which allow the transfer of information from the control unit. The
wCU uses ZigBee technology to design wireless sensor network. Here ZigBee end devices are connected to relay driver circuit to control the electromagnetic door lock module. The wIU uses Raspberry Pi as its processing unit. Model $\mathrm{B}+$ of $\mathrm{Pi}$ is used in this work. It contains a System on Chip (SoC) named вСм2835 that is found in many mobile phones. The SoC integrates an ARM1176JZ-F processor, a graphic processing unit named Video Core IV and $512 \mathrm{MB}$ ram into a single unit. This model has 40 GPIO pins, 4 UsB ports and an Ethernet port. Pi doesn't have a persistent internal memory so it is booted up from SD card. A camera unit is connected to Pi to capture images of visitors. To access and send emails to the consumer python-coded algorithm that is fed into it.

For transmitting data via mobile networks a GPRS module is also available in wiU. This module can send alert sms about the visitors to the concerned authorities. Data captured by smart camera is transmitted over the Internet by integrating an Internet gateway with ZigBee network. In a ZigBee network end devices collect and forward data to a coordinator and then ZigBee protocol data format is translated to internet protocol (IPv6) format by the gateway. The proposed design consists of the following modules and is described briefly.

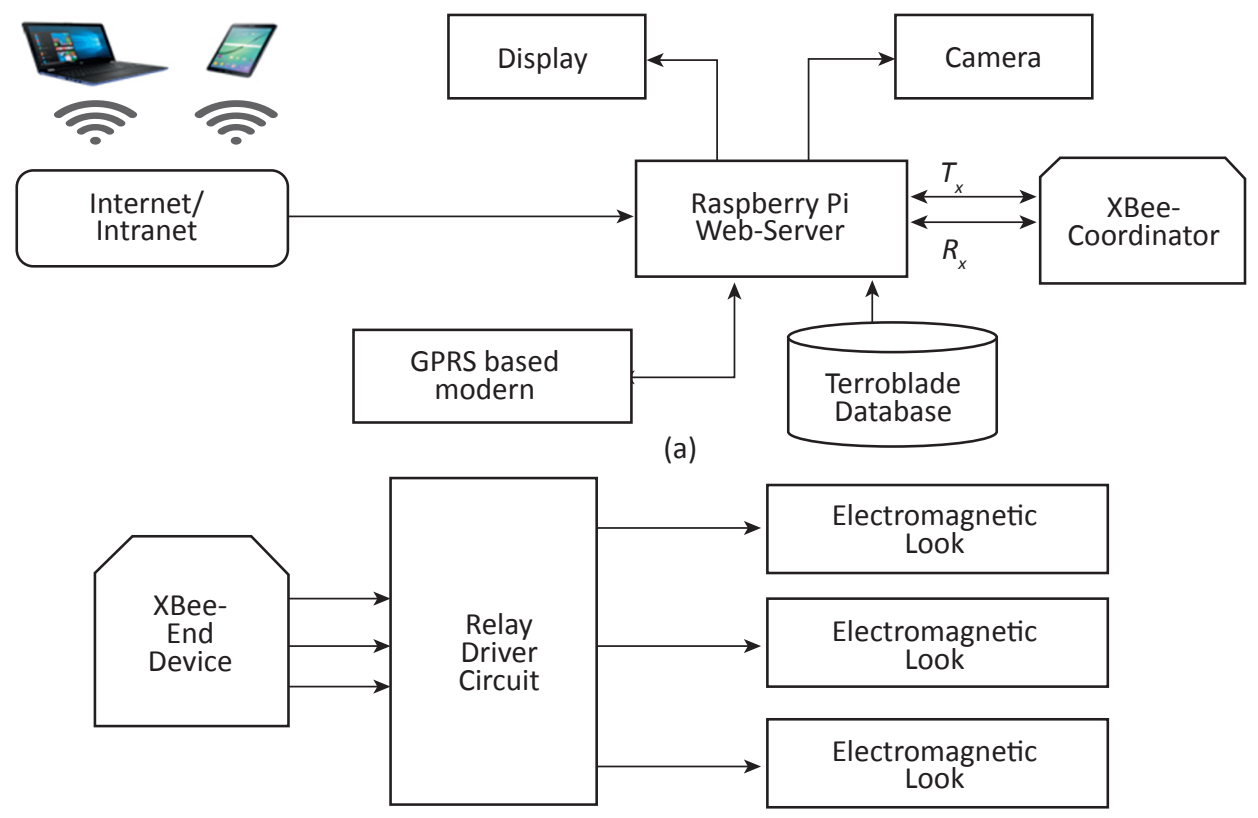

Fig. 9. Layout of the proposed system configuration; (a) Wireless Information Unit, (b) Wireless Control Unit Reference: [7] 


\subsection{Zigbee Module}

The proposed phone security system uses ZigBee communication technology. This technology is energy efficient, self-configuring, low cost and yet gives high accuracy [20]-[22]. In the proposed system the control module and the sink module use ZigBee platform for communication. XBee S2 module working on $2.4 \mathrm{GHz}$ band has been used. Although this module works in $2.4 \mathrm{GHz}$ band, it transmits data and receives them serially. The configuration of ZigBee module has been done through X-CTU software. In this system network it is possible to converse 8 data modules to the single sink module, which is coupled to a Raspberry $\mathrm{Pi}$. The private area network ID remains the same as that of developed control and sink modules. If proper configuration is done, network connection between the control modules and sink node is automatically established. Each component of the system is configured to send their status every 4 seconds to the coordinators.

\subsection{Lock Module}

The Lock module consists of a ZigBee end device (ZED), a lock for each instance and a control circuit. For operating the ZED a $5 \mathrm{v}$ DC circuit has been used. The ZED circuit controls the lock through control circuit.

\subsection{Iот Application Gateway}

The program at the гот application gateway executes the transformation of control information between the ZigBee and IPv6 network, since the architecture to communicate with Internet protocols is lacking in the ZigBee network. The ZigBee address is transformed and data payloads are encapsulated in an internet protocol in the IoT application gateway. The sample packets produced by the XBee-S2 module are converted to IPv6 user datagram packets (UDP) by the application gateway and sent to the server. To control the XBee-S2 module by the server, the command packet encapsulated in UDP packets is converted to ZigBee packets by the IoT application gateway.

\section{5. sMs Module}

This module comprises of GPRS/GSM modem and control program. The GSM modem is connected to the Raspberry Pi via serial interface to the switching module. The sms module acts as an interface between the embedded processor and the Gsm network. The embedded gateway stores the GSM dialup, communication protocol and control program. The system logs into the network and makes data transfer and communication through the SMS module. The GSM/GPRs module used is SIM900A. It operates on various frequencies such as $880 \mathrm{MHz}$, $900 \mathrm{MHz}, 1800 \mathrm{MHz}$ and $1900 \mathrm{MHz}$ to send sMs. The modem connects to microcontroller's serial interface via an RS232 level converter circuit. The TCP/IP stack present in modem enables the microcontroller to connect to the Internet via GPRs. To communicate with homeowner an sMs activation system is implemented. The module takes the AT command from a remote terminal or mobile device and sends them to switching module via the GSM network.

The embedded web server is developed in the Linux environment supporting SLIP, TCP/IP, HTTP and AT commands protocol and it is implemented on the Raspberry Pi development board. The dynamically generated files, which could include output data from hardware resources, is supported by web server's flash file system and is called an Embedded Server Page (ESP).

\subsection{Embedded Server Pages}

The embedded server page is created using the following languages: HTML, JavaScript, PHP and sQLite. Users can add embedded equipment data in a page using dynamic HTML. Dynamic HTML gives access to the user to both control and observe in a secure environment. Fig.10 shows the login page.

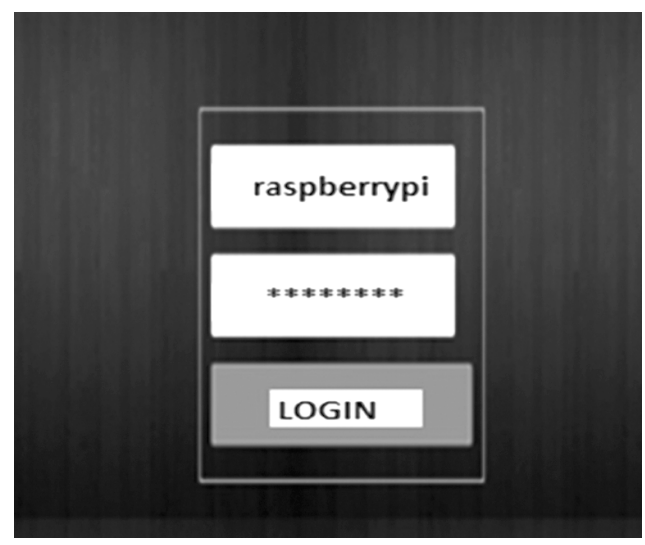

Fig. 10. Login page

Reference: the authors 
JavaScript enables user-friendly interaction with equipment to HTML. Resizing of the data field of HTML pages and validation of the input field is done with JavaScript.

sQLite is used as embedded database to store locally in application software's such as embedded equipment data records for present and future use of the web browsers. SQLite is extensively used today by several widespread browsers, operating systems and embedded systems. It is arguably the most widely deployed database engine.

\section{Discussion}

A notification email and/or sms indicating the update regarding the visitor is sent by the wIU module to authorized users. The algorithm reads the subject and checks for the existence of a safe range of devices wirelessly. The data is then forwarded to wCU for further processing. If all the safety and security norms are satisfied by the system, then wIU forwards controlling commands to wCU wirelessly. The wCU now performs the necessary switching action. In the given experimental setup an email with subject onl was sent to the Raspberry Pi account (rpi.home3@gmail.com) from the authorized users account (agrawalrishabh3@gmail.com)

\section{Conclusions}

We have proposed this model for disease detection and monitoring patients at remote locations. The distributed agents are proposed to act on a common platform using Internet for the benefit of society. The system database stores all the attributes for future reference and implementation of fuzzy inference system for diagnosis, which saves time for physicians as well as the travelling costs for the patient. This ingenious idea can be implemented to other crucial areas for future work like disaster management, green house monitoring, food and agriculture industry, etc.

\section{References}

[1] H. D. Lee, A. Rabbi, J. Choi, and R. F. Rezai, "Development of a Mobile Phone Based e-Health Monitoring
Application," International Journal of Advanced Computer Science and Applications, vol. 3, no. 3, pp. 38-43,2012. doi: http://dx.doi.org/10.14569/IJACSA.2012.030307

[2] J. C Su, "Mobile multi-agent based, distributed information platform (MADIP) for wide-area e-health monitoring", Computers in Industry, vol. 59, pp: 55-68, 2008. doi: https://doi.org/10.1016/j.compind.2007.06.001

[3] N. Benhajji, D. Roy, and D. Anciaux, "Patient-centered multi agent system for health care", ${ }_{F A C-P a-}$ pers On Line, vol. 48, no. 3, pp: 710-714, 2015. doi: https://doi.org/10.1016/j.ifacol.2015.06.166

[4] G. B. Silverman, N. Hanrahan, G. Bharathy, K. Gordon, and D. Johnson, "A systems approach to healthcare: Agent-based modeling,community mental health, and population well-being", Artificial Intelligence in Medicine, vol. 63, pp. 61-71, 2015. doi: https://doi.org/10.1016/j.artmed.2014.08.006

[5] H. O. Al-Sakran, "Framework architecture for improving healthcare information systems using agent technology", International Journal of $\mathrm{Ma}$ naging Information Technology, vol. 7, no. 1, pp. 17-31,February2015. doi: http://dx.doi.org/10.5121/ ijmit.2015.7102

[6] K. AlSharqi, A. Abdelbari, A. Abou-Elnour, and M. Tarique, "Zigbee based wearable remote healthcare monitoring system for elderly patients", International Journal of Wireless \& Mobile Networks (IJWMN), vol. 6, no. 3, pp. 53-67, 2014. doi: http://dx.doi. org/10.5121/ijwmn.2014.6304

[7] M. N Mohanty, "An Embedded Approach for Design of Cardio Monitoring System", Adv. Science Letters, vol. 22, no. 2, pp. 349-353, 2016. doi: https://doi. org/10.1166/asl.2016.6854

[8] M. Singh, M. N. Mohanty, and R. N. D. Choudhury, "An Embedded Design for Patient Monitoring and Telemedicine", Int.Journal of Electrical, Electronics \& Computer Engineering", vol. 2, no. 2, pp. 66-71, 2013, [Online]. Available: http://citeseerx.ist.psu. edu/viewdoc/download?doi=10.1.1.668.3590\&re$\mathrm{p}=$ rep $1 \&$ type $=$ pdf

[9] C. S. Devi, G. G.Ramani, and J. A. Pandian, "Intelligent E-Healthcare Management System in Medicinal Science", International Journal of PharmTech Research, vol. 6, no. 6, pp. 1838-1845,Oct-Nov. 2014, [Online]. Available http://www.sphinxsai. com/2014/ph_vol6_no6/2/(1838-1845)\%20014.pdf

[10] E.E. Elavathingal and T.K. Sethuramalingam, "A Survey of E-Healthcare Systems Using Wearable Devices and Medical Sensor Networks", Karpagam journal of engineering research (KJER), vol. 1, no. 1, 2014, [Online]. Available: https://www.researchgate.net/profile/Ebin_Elavathingal/publication/271832274_A_ 
Survey_of_EHealthcare_Systems_Using_Wearable_Devices_and_Medical_Sensor_Networks/ links/ 54d308980cf2b0c6146ca01b.pdf

[11] S. Tupe and N. P. Kulkarni, "ECA: Evolutionary Computing Algorithm for E-Healthcare Information System", in iPGCON-2015, 24-25 March 2015, [Online]. Available:http://spvryan.org/splissue/ipgcon/063.pdf

[12] M. Shouman, T. Turner, and R. Stocker, "Using Decision Tree for Diagnosing Heart Disease Patients", Conferences in Research and Practice in Information Technology (CRPIT), vol. 121, pp. 23-29, 2011, [Online]. Available: http://crpit.com/confpapers/CRPITV121Shouman.pdf

[13] M. Shouman, T. Turner, and R. Stocker, "Applying k-Nearest Neighbour in Diagnosing Heart Disease Patients", International Journal of Information and Education Technology, vol. 2, no. 3, pp. 220-223, June 2012. doi: https://doi.org/10.7763/ijiet.2012.v2.114

[14] D. Mandal, I. M. Chattopadhyay, and S. Mishra, "A Low Cost Non-invasive Digital Signal Processor Based (TMS320C6713) Heart Diagnosis System", Int. Conf. on Recent Advances in Information Techno$\log y,(R A I T), 2012$. doi: https://dx.doi.org/10.1109/ RAIT.2012.6194535

[15] Q. A. Rahman, L. G. Tereshchenko, M. Kongkatong, T. M. Abraham, M. R. Abraham, and H.Shatkay, "Utilizing ECG-Based Heartbeat Classification for Hypertrophic Cardiomyopathy Identification", IEEE transactions on nanobioscience, vol. 14, no. 5, pp. 505-512, July 2015. doi: https://dx.doi.org/10.1109/ TNB.2015.2426213
[16] L. Sarangi, M. N. Mohanty, and S. Patnaik, "An Intelligent Decision Support System for Cardiac Disease Detection",International Journal of Control Theory and Applications, vol. 8, no. 5, pp. 2137-2143, 2015, [Online]. Available:http://www.serialsjournals.com/ serialjournalmanager/pdf/1460974653.pdf

[17] L. Sarangi, M. N. Mohanty, and S. Patnaik, "Critical Heart Condition Analysis through Diagnostic Agent of e-Healthcare System using Spectral Domain Transfom", Indian Journal of Science \& Techno$\log y$, vol.9, no. 38, pp.1-6, 2016. doi: https://dx.doi. org/10.17485/ijst/2016/v9i38/101937

[18] M. Schmidt, Raspberry Pi.A Quick Start Guide, Dallas, Texas: The Pragmatic Bookshelf, 2012, pp. 11-42.

[19] XBee-PRo RF Module. Digi Int. Inc., Hopkins, MN, usA. [Online]. Available: http://www.digi.com

[20] M. Guan and M. Gu, "Design and implementation of an embedded web server based on ARM", IEEE International Conference on Software Engineering and Service Sciences (ICSESS), vol. 16, no. 18, 2010. doi: https://dx.doi.org/10.1109/ICINDMA.2010.5538305

[21] IEEE Standard for Information Technology-Telecommunications andInformation Exchange between Systems-Local and Metropolitan AreaNetworks, IEEE Standard 802.15.4-2003, (2003). doi: https://dx.doi. org/10.1109/IEEESTD.2003.94389

[22] Rhydo Technologies, "SIM9oo GSM/GPRS RS232 Modem - UserManual”, (Dec, 2011). 